\title{
T.3. Шахбазян
}

\section{ГЕОИНФОРМАЦИОННЫЙ АНАЛИЗ ДЛЯ ЦЕЛЕЙ ФОРМИРОВАНИЯ ЭКОЛОГИЧЕСКОГО КАРКАСА И РАСШИРЕНИЯ СЕТИ ООПТ (НА ПРИМЕРЕ СТАВРОПОЛЬСКОГО КРАЯ)}

\begin{abstract}
АННОТАЦИЯ
В статье обсуждаются вопросы проектирования экологического каркаса региона с помощью геоинформационных технологий. В качестве территории исследования выступает Ставропольский край, имеющий развитую сеть особо охраняемых территорий (ООПТ), вместе с тем выступающий связующим звеном между ООПТ Северного Кавказа и степными ООПТ Прикаспийской низменности. В качестве программного обеспечения в работе использовалась ГИС Quantum GIS. Основой методики выступил геоинформационный анализ природных и антропогенных факторов. Проектирование экологического каркаса основывается на методе автоматизированной обработки пространственных данных. Исходными данными в работе выступили векторные пространственные данные, характеризующие природные условия и антропогенную освоенность. При анализе использовался метод гексагональных операторов (ячеек), минимальной территориальной единицей выступили соты со стороной 5 км. В работе использовался алгоритм обработки векторных данных, основанный на делении векторных объектов по геометрическим признакам. Для группирования разнородных векторных данных использовалась методика присвоения балльных значений. Балльные значения присваивались при помощи алгоритма классификаций Дженкенса, для автоматизации присвоения балльных значений использовался алгоритм обработки атрибутивных данных, основанный на операторе «case». Ядром методики стала формула, отражающая разность природных и антропогенных факторов на исследуемой территории. По векторным пространственным данным была получена интегральная оценка территории, на основании которой выделялись элементы экологического каркаса Ставропольского края. На базе спроектированного экологического каркаса выделялись перспективные территории для новых ООПТ. В работе предложено 9 природно-территориальных комплексов под перспективные ООПТ. При выделении новых ООПТ автор руководствовался принципами репрезентативности сети и ландшафтного подхода, ввиду чего перспективные ООПТ были заложены в провинциях степных и полупустынных ландшафтов, в которых наблюдается недостаток на сегодняшний день.
\end{abstract}

КЛЮЧЕВЫЕ СЛОВА: особо охраняемые природные территории, ГИС-анализ, ландшафты Ставропольского края, ГИС-анализ природных факторов

\footnotetext{
${ }^{1}$ Северо-Кавказский федеральный университет, Кафедра социально-экономической географии, геоинформатики и туризма, ул. Пушкина, д. 1, 355000, Ставрополь, Россия;

e-mail: tt89620110598@yandex.ru
} 
Tigran Z. Shahbazyan ${ }^{1}$

\author{
GIS-ANALYSIS FOR THE PURPOSES \\ OF THE ECOLOGICAL FRAMEWORK FORMATION \\ AND EXPANSION OF THE NETWORK OF PROTECTED NATURAL AREAS \\ (ON THE EXAMPLE OF STAVROPOL TERRITORY)
}

\begin{abstract}
The article discusses the issues of designing the ecological framework of the region with the help of geoinformation technologies. The research area is the Stavropol Territory, which has a developed network of specially protected areas, at the same time acting as a link between the protected areas of the North Caucasus and the steppe protected areas of the Caspian lowland. Quantum GIS was used as software in the work. The basis of the methodology was the geoinformation analysis of natural and anthropogenic factors. The design of the ecological framework is based on the method of automated spatial data processing. The initial data in the work were vector spatial data characterizing natural conditions and anthropogenic development. The analysis used the method of hexagonal operators (cells), the minimum territorial unit is a cell with a side of $5 \mathrm{~km}$. The author Developed an algorithm for processing vector data based on the division of vector objects by geometric features. To group heterogeneous vector data, the method of assigning point values was used. Point values were assigned using the Jenkens classification algorithm, and an attribute data processing algorithm based on the "case" operator was used to automate the assignment of point values. The core of the method was the formula reflecting the diversity of natural and anthropogenic factors in the study area. On the basis of vector spatial data, an integral assessment of the territory was obtained, on the basis of which the elements of the ecological framework of the Stavropol territory were distinguished. On the basis of the designed ecological framework, promising areas for new protected areas were allocated. The paper proposes 9 natural-territorial complexes for promising protected areas. In identifying new protected areas, the author was guided by the principles of representativeness of the network and landscape approach, which is why promising protected areas were laid in the provinces of steppe and semi-desert landscapes, in which there is a shortage today.
\end{abstract}

KEYWORDS: protected areas, GIS-analysis, landscapes of Stavropol Territory, GIS-analysis of natural factors

\title{
ВВЕДЕНИЕ
}

Интенсивное освоение Ставропольского края в XX в. способствовало антропогенной трансформации ландшафтов; на сегодняшний день около 60 \% территорий региона распахано. Для сохранения ландшафтного разнообразия на территории края организована сеть особо охраняемых природных территорий (ООПТ).

Формирование сети ООПТ Ставропольского края происходило на протяжении почти 60 лет; современная сеть особо охраняемых природных территорий в Ставропольском крае представлена 108 ООПТ. В их числе - национальный парк федерального значения, 41 государственный природный заказник, 65 памятников природы и 1 охраняемая озеленённая и лесная территория.

Площадь особо охраняемых природных территорий в Ставропольском крае составляет около 125 тыс. га или 1,6 \% от общей площади Ставропольского края. Площадь национального парка - 965,8 га, государственных природных заказников — 98 551,33 га, площадь памятников природы — 15772,32 га, площадь охраняемой

\footnotetext{
${ }^{1}$ North-Caucasian Federal University, Department of Socio-Economic Geography, Geoinformatics and Tourism, Pushkin str., 1, 355000, Stavropol, Russia; e-mail: tt89620110598@yandex.ru
} 
озеленённой и лесной территории составляет 12,63 га. Стоит отметить, что при расчётах не учитывается площадь 19 памятников природы (7,87 тыс. га), которые расположены на территории государственных природных заказников.

Для более детального понимания структуры сети ООПТ Ставропольского края стоит выделить основные элементы сети. Ключевые элементы провинции среднегорных степных и лесостепных ландшафтов: Национальный парк «Кисловодский», заказники Малый Ессентучок», «Большой Ессентучок», «Бугунтинский». Ядром Провинции среднегорных ландшафтов и остепенённых лугов является заказник «Бештаугорский». Основные элементы провинции лесостепных ландшафтов заказники «Александровский», «Русский лес», «Стрижамент». Осевыми элементами провинции степей являются заказники «Бурукшунский», «Лесная Дача», «Красногвардейский», «Новотроицкий», «Арзгирский». Ландшафты Терско-Кумской низменности испытывают недостаток в ООПТ, однако стоит отметить основные элементы: заказники «Иргаклинский», «Восточный», «Дюна». В ландшафтах Кумо-Маныческой впадины ядрами являются заказники «Чограйский» и «Маныч-Гудило».

Согласно представлениям Д.В. Черных, все ООПТ в границах определённой территории являются сетью ООПТ [Черных, 2008]. Однако для их эффективного функционирования в условиях нарастающего антропогенного воздействия необходимо руководствоваться принципами функционально целостной системы при организации сетей ООПТ.

Под системой ООПТ понимается совокупность различных категорий резерватов, функционально и территориально связанных между собой через различные формы вещественно-энергетического и информационного взаимодействия [Иванов, 2003, с. 49].

Для сочетания природоохранных и хозяйственных направлений деятельности человека предусмотрена концепция экологического каркаса.

Под экологическим каркасом Е.Ю. Колбовский понимает «полярно дистанцированную от центров и осей хозяйственной деятельности композицию природных (диких) и культурных экосистем, построенную на основе крупных резерватов, соединённых экологическими коридорами, обеспечивающую экологическую стабильность (относительный гомеостаз) вмещающего пространства соответствующего уровня (региона, хозяйства, территории сельского самоуправления, городского округа)» [Колбовский, 2008, с. 71].

В.В. Владимиров считал, что экологический каркас состоит из ООПТ, которые являются ядрами, а также коридоров и буферных зон, которые обеспечивают функциональную связь между ядрами экологического каркаса [Владимиров, 1995]. Экологический каркас любой территории включает в себя площадные, линейные, точечные объекты и буферные зоны [Георгица, 2006].

К площадным объектам относят национальные и природные парки, заповедники, заказники, к линейным - русла и поймы рек, водоразделы, защитные лесопосадки, к точечным - памятники природы различного уровня. Буферные зоны включают водоохранные, санитарно-защитные, курортные зоны [Георгища, 2006, с. 5].

На сегодняшний день сеть особо охраняемых природных территорий в Ставропольском крае далека от функционально целостной системы. Данная ситуация обусловлена многими факторами, среди которых отсутствие на территории края федеральных заповедников, которые являются мощными ядрами экологического каркаса, а также стихийное формирование ООПТ на территории края. Кроме того, высокая освоенность человеком создает дополнительные сложности при поиске мест для создания особо охраняемых природных территорий.

На сегодняшний день ведущим методом проектирования экологического каркаса является картографический метод, однако проблемным остается вопрос критериев выделения экологического каркаса [Лопаткин, 2004]. 
В данном аспекте наиболее актуальным методом проектирования экологического каркаса является метод выделения его элементов, основанный на автоматизированной обработке пространственных данных.

Наиболее репрезентативным методом обработки данных в таких случаях выступает геоинформационный метод, а именно метод геоинформационного анализа.

Цель статьи - провести геоинформационный анализ природных и антропогенных условий Ставропольского края для целей проектирования экологического каркаса и расширения сети ООПТ.

\section{МАТЕРИАЛЫ И МЕТОДЫ ИССЛЕДОВАНИЙ}

В качестве исходных данных использовались векторные данные, характеризующие природные условия (реки, озёра, лесные насаждения) и антропогенную освоенность (селитебные территории, транспортные узлы).

В качестве методики анализа использовался метод гексагональных операторов (ячеек), который показал эффективность при анализе природных и экономических условий для целей туризма и рекреации [Дунец, 2011; Дирин, 2017]. В качестве программного обеспечения использовалась Quantum GIS (версия 3.3).

В качестве минимальной территориальной единицы использовались соты со стороной 5 км, размер ячейки вычислялся опытным путём. Стоит отметить, что при выборе размера ячейки имеет смысл руководствоваться принципами генерализации, при выборе более мелких операторов возникают шумы, которые усложняют обработку результатов анализа, при избыточных размерах оператора теряется точность, ввиду чего выделить необходимые территории становится сложнее. Пример использования различных операторов представлен на рис. 1 .

Имеющиеся векторные пространственные данные можно разделить на 2 класса площадные (полигональные) и линейные объекты. Каждый класс объектов имеет свои особенности обработки, подробный алгоритм обработки векторных данных и геоинформационного анализа представлен на блок-схеме (рис. 2).

После первичного анализа векторных данных было необходимо привести данные к единому виду; эта мера была необходима ввиду того, что в ходе анализа мы использовали 2 класса векторных данных, следовательно 2 класса единиц измерения, а именно единицы длин (м) и единицы площадей $\left(\mathrm{M}^{2}\right)$.

В качестве методики приведения к общему виду данных мы использовали методику классификации массивов данных Дженкинса с присвоением балльных значений.

В методе естественных границ классы основаны на естественном группировании данных. Границы классов определяются таким образом, чтобы сгруппировать схожие значения и максимально увеличить различия между классами. Объекты делятся на классы, границы которых устанавливаются там, где встречаются относительно большие различия между значениями данных.

Далее при помощи модуля «Калькулятор полей», сгруппированным по методу Дженкинса интервалам присваивались балльные значения; для этого использовались команды с оператором «Case». Пример присвоения балльных значений для слоя «Реки» отображен на рис. 3).

После присвоения балльных значений с помощью функции «связь таблиц» оценки группировались в одну таблицу, после чего можно было проводить расчёты. В нашей работе мы использовали следующую формулу:

$$
\text { ИОТ }=\sum \Phi_{п}-\sum \Phi_{\mathrm{a}}(\text { формула } 1),
$$

где ИОТ - интегральная оценка территории, $\Phi_{п}-$ природных факторов, $\Phi_{\text {a }}$ - антропогенных факторов. 

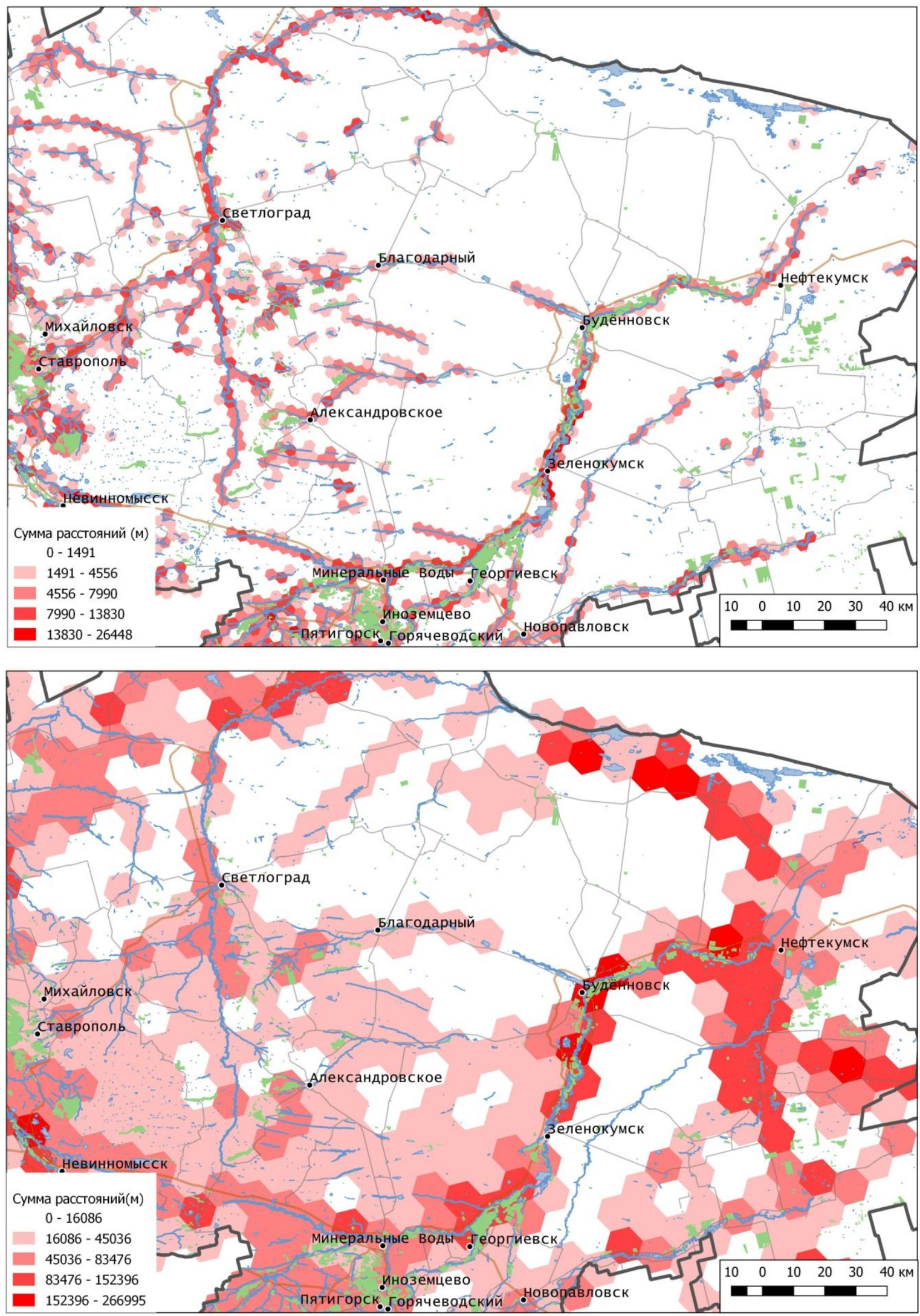

Рис. 1. Анализ рек модулем "Сумма расстояний», оператор 5 км сверху и 15 км снизу Fig. 1. Analysis of rivers by the module "sum of distances", operator $5 \mathrm{~km}$ from the top and $15 \mathrm{~km}$ from the bottom 


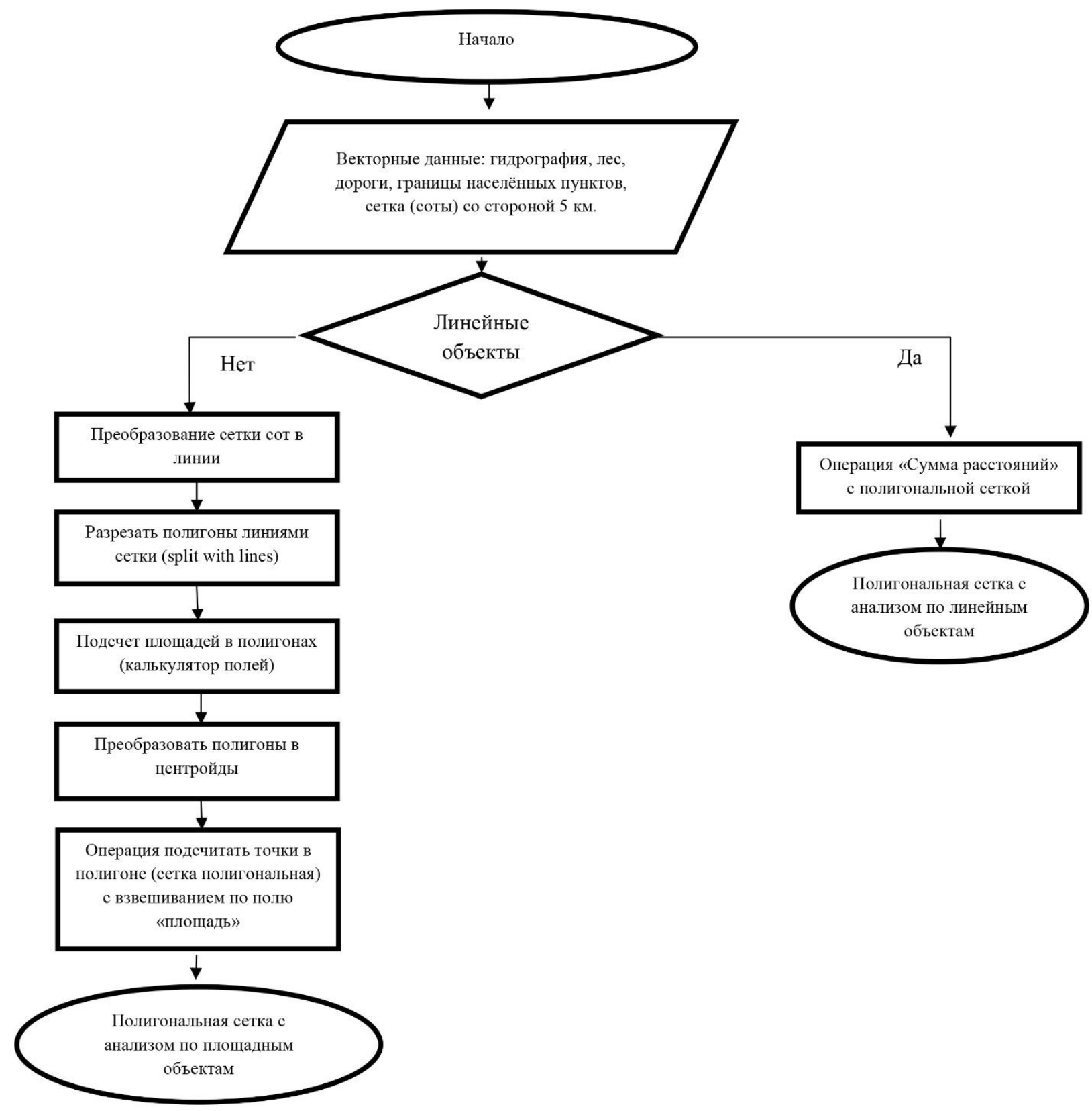

Рис. 2. Блок-схема алгоритма обработки векторных данных и геоинформационного анализа

Fig. 2. The block diagram of the algorithm of processing vector data and GIS analysis

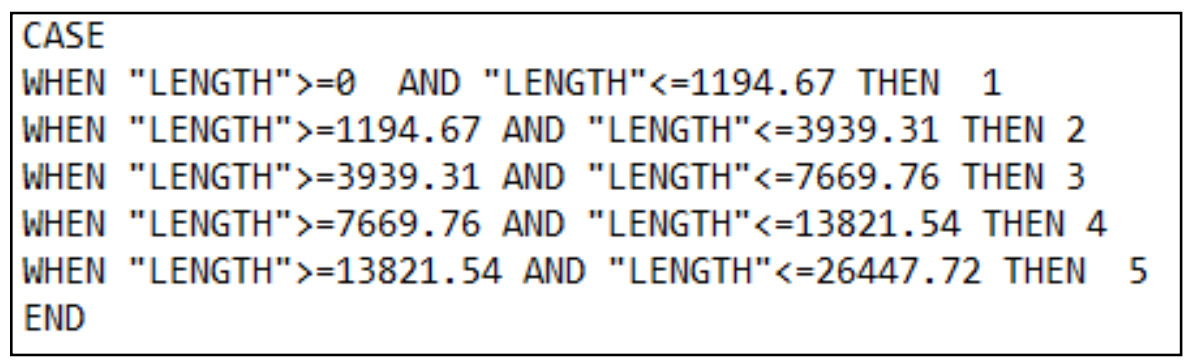

Рис. 3. Блок-схема алгоритма обработки векторных данных и геоинформационного анализа

Fig. 3. The block diagram of the algorithm of processing vector data and GIS analysis 


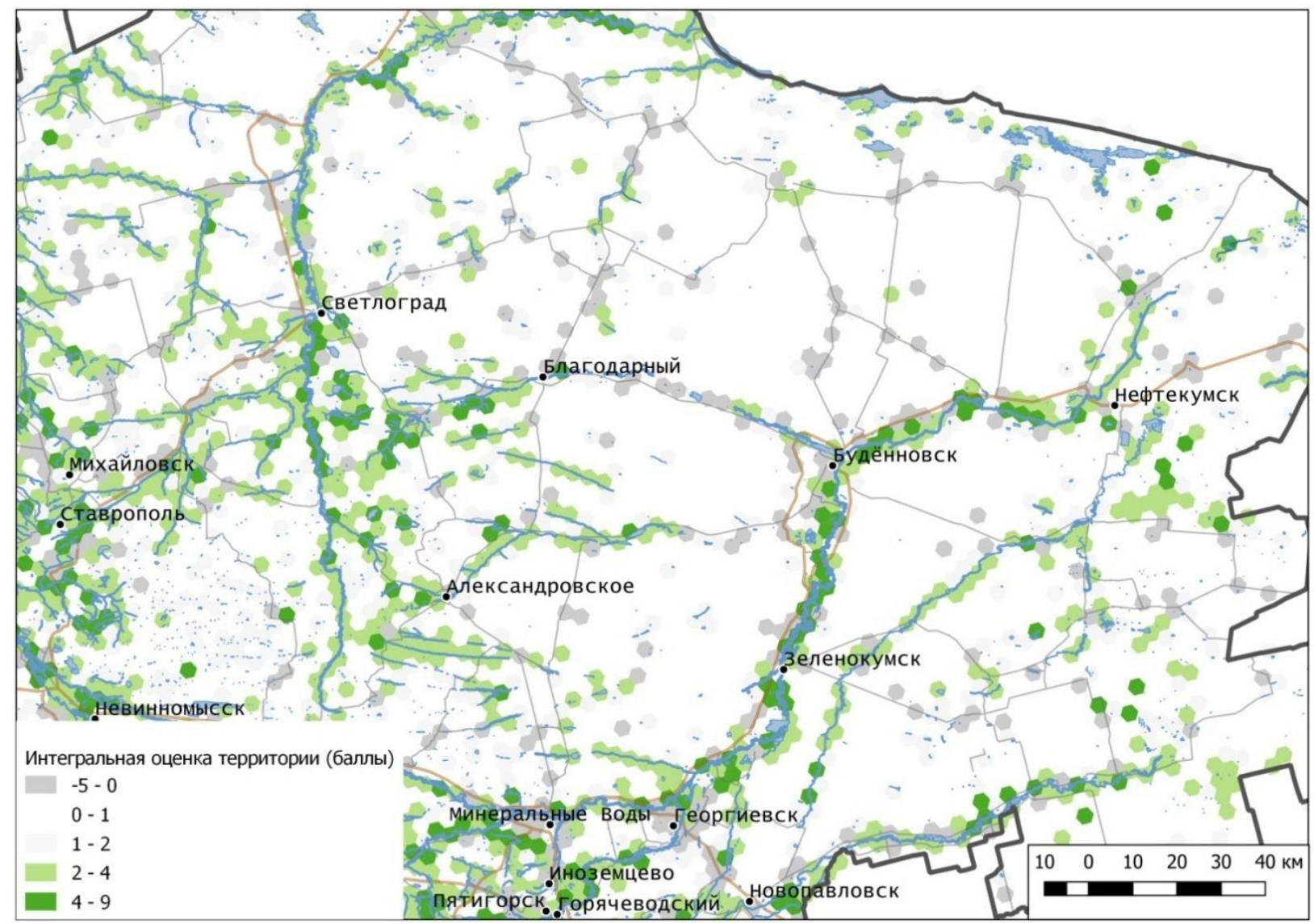

Рис. 4. Сетка сот с интегральной оценкой территории для иелей проектирования экологического каркаса, рассчитана согласно формуле 1.

Fig. 4. The grid of honeycombs with integrated assessment of the territory for the purposes of designing the ecological framework calculated according to formula 1.

По итогам расчётов мы получили сетку сот, где каждая ячейка отражает интегральную оценку территории для целей проектирования экологического каркаса (рис. $3)$.

В качестве природных факторов учитывались лесные насаждения и водные объекты, в качестве антропогенных факторов - транспортная инфраструктура и селитебные территории.

Ячейкам с отрицательными бальными значениями, как правило, соответствуют селитебные территории и транспортные развязки, значения 0-2 балла приобретают территории сельскохозяйственных угодий, значения 2-4 балла приобретают территории со слаборазвитой речной сетью и разреженной лесной растительностью, территории со значениями выше 4 баллов - леса и поймы крупных рек.

Для избавления от шумов и приведения к более привычному и читаемому виду по данным анализа вручную отображались экологические коридоры.

\section{РЕЗУЛЬТАТЫ ИССЛЕДОВАНИЙ И ИХ ОБСУЖДЕНИЕ}

По итогам исследований была получена карта экологического каркаса Ставропольского края, на которой были отображены экологические коридоры, связывающие ООПТ Ставропольского края. Коридоры расположились преимущественно на поймах рек и лесных насаждениях.

Следующим шагом в нашей работе было определение территорий для перспективного расширения сети ООПТ Ставропольского края. В качестве методической 
основы расширения сети ООПТ использовался ландшафтный подход. В предыдущих исследованиях мы определили, что недостаток ООПТ наблюдается в провинциях степных и полупустынных ландшафтов [Лысенко, Шахбазян, 2018].

Руководствуясь принципами функционально целостной системы [Иванов, 2003], мы решили, что наилучшим вариантом будет расположить перспективные ООПТ на природно-территориальных комплексах, находящихся непосредственно на экологических коридорах. Список проектируемых ООПТ приведён в табл. 1.

\section{Табл. 1. Список проектируемых ООПТ}

Table 1. List of projected protected areas

\begin{tabular}{|r|l|l|}
\hline № & \multicolumn{1}{|c|}{ Название } & \multicolumn{1}{|c|}{ Местоположение } \\
\hline 1 & Пойма р. Бол. Кугульта & Труновский район \\
\hline 2 & Пойма р. Грязнушка & Благодарненский городской округ \\
\hline 3 & Пойма р. Кума (с. Нины) & Советский городской округ \\
\hline 4 & Озеро Давсун & Арзгирский район \\
\hline 5 & Лес Мулюшкино 2 & Курский район \\
\hline 6 & Лес Мулюшкино & Курский район \\
\hline 7 & Пойма р. Кума (с. Урожайное) & Левокумский район \\
\hline 8 & Озеро Лысый лиман & Апанасенковский район \\
\hline 9 & Пойма р. Калаус (Воздвиженское) & Апанасенковский район \\
\hline
\end{tabular}

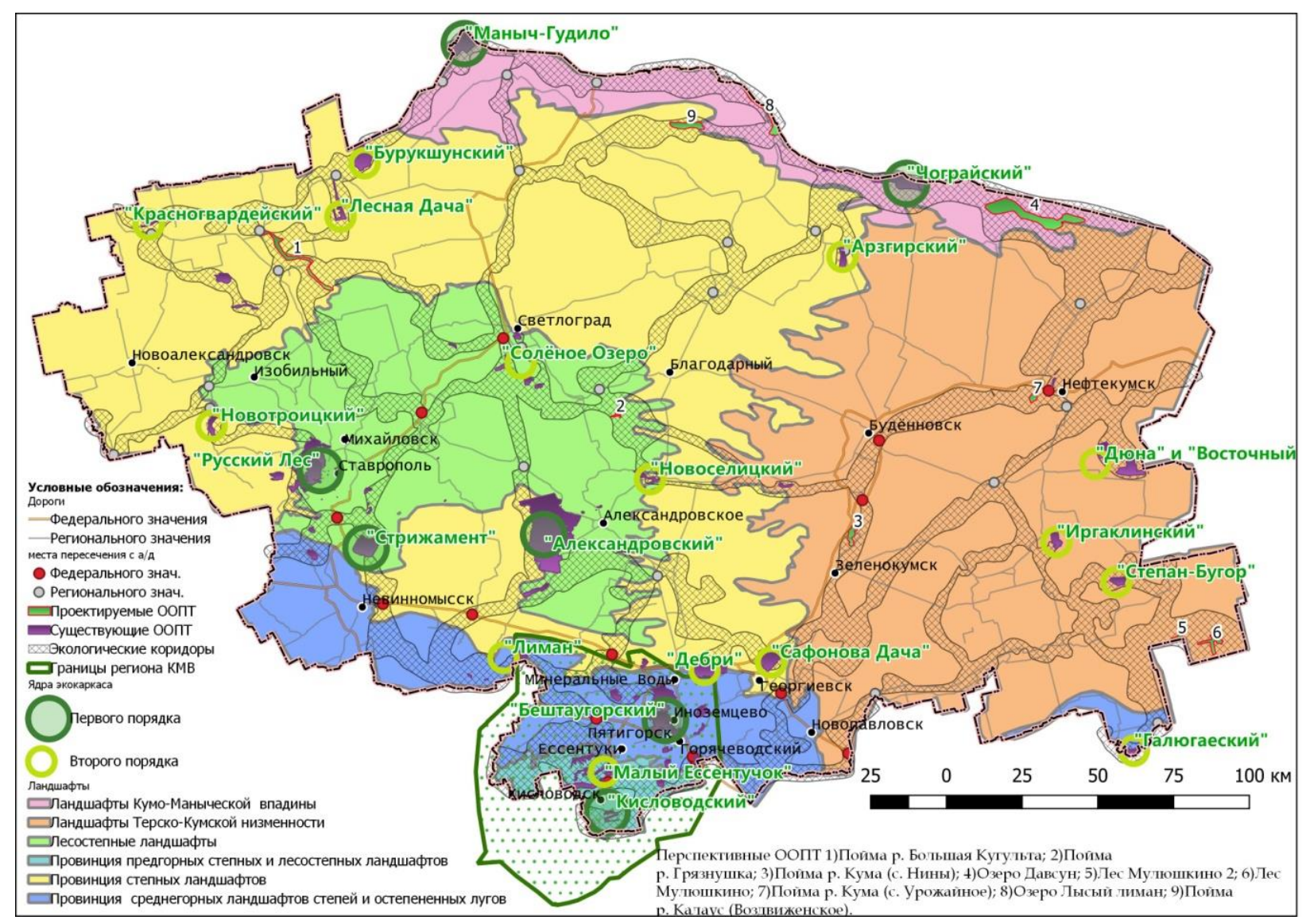

Рис. 5. Карта-схема экологического каркаса Ставропольского края Fig. 5. Map of ecological framework of Stavropol region 
Спроектированный экологический каркас свяжет в единую сеть особо охраняемые природные территории Ставропольского края, а также обеспечит транзитные связи между заповедниками Кавказа и Прикаспийской низменности. Кроме того, проектируемые ООПТ усилят функциональные связи в сети, а также повысят её репрезентативность включением природно-территориальных комплексов степных и полупустынных ландшафтов.

\section{ВЫВОДЫ}

1. Концепция экологического каркаса позволяет сочетать природоохранную и хозяйственную деятельность, сохраняя при этом вещественно-энергетические связи ландшафтов.

2. Метод геоинформационного анализа позволяет наиболее объективно выделить элементы экологического каркаса, опираясь на природные условия и антропогенную освоенность региона.

3. При проектировании экологического каркаса Ставропольского края ядрами каркаса выступили ООПТ, экологическими коридорами - русла рек и защитные лесные насаждения.

4. В ходе исследования нам удалось выделить ядра экологического каркаса 1-го и 2-го порядков. Ядрами первого порядка выступали ООПТ, имеющие центральное значение в формировании каркаса края, ядрами второго порядка выступали ООПТ, являющиеся в первую очередь узловыми единицами ландшафтных районов.

5. Экологические коридоры каркаса не только обеспечивают связи ООПТ Ставропольского края, но и выполняют транзитные функции между заповедниками Кавказа и степными заповедниками Прикаспийской низменности.

6. Проектируемые ООПТ позволят расширить сеть ООПТ, повысив при этом репрезентативность сети включением в неё ООПТ степных и полупустынных ландшафтов, в которых наблюдается недостаток на сегодняшний день.

\section{СПИСОК ЛИТЕРАТУРЫ}

1. Владимиров В.В., Фомин И.А. Основы районной планировки. М.: Высшая школа, 1995. $221 \mathrm{c}$.

2. Георгииа И.М. Ландшафтно-географический подход к конструированию экологического каркаса городов (на примере Ярославля). Автореферат дисс. ... канд. геогр. н. Астрахань: Астраханский государственный университет, 2006. 20 с.

3. Дирин Д.А., Крупочкин Е.П., Рыгало Е.В. Геоинформационная оценка туристскорекреационного потенциала степных территорий (на примере Кулундинской степи). ИнтерКарто. Интер ГИС. Геоинформационное обеспечение устойчивого развития территорий в условиях глобальных изменений климата: Материалы Междунар. конф. Т. 23. Ч. 2. М.: Издательство Московского университета, 2017. С. 89-102.

4. Дунец А.Н., Крупочкин Е.П., Тельияова А.А. Оценка туристско-рекреационного потенциала для целей территориального планирования. Известия АлтГУ, 2011. № 3-2. Электронный pecypc: https://cyberleninka.ru/article/n/otsenka-turistsko-rekreatsionnogopotentsiala-dlya-tseley-territorialnogo-planirovaniya (дата обращения 13.11.2019).

5. Иванов А.Н., Чижова В.П. Охраняемые природные территории: Учебное пособие. М.: Издательство Московского университета, 2003. 119 с.

6. Колбовский Е.Ю., Ландшафтное планирование: учеб. пособие для студ. высш. учеб. заведений. М.: Академия, 2008. 336 с.

7. Лопаткин Д.А. Картографическое отображение и анализ экологического каркаса региона (на примере бассейна оз. Байкал). Автореферат дисс. ... канд. геогр. н. Иркутск: Институт географии СО РАН, 2004. 23 с. 
8. Лысенко А.В., Шахбазян Т.З. Ландшафтно-экологический анализ сети особо охраняемых природных территорий Ставропольского края с применением геоинформационных технологий. Третья междунар. науч. конф. с элементами научной школы «Инновационные методы и средства исследований в области физики атмосферы, гидрометеорологии, экологии и изменения климата». Ставрополь: Изд-во СКФУ, 2018. С. 285-287.

9. Родоман Б.Б. Поляризованная биосфера: Сборник статей. Смоленск: Ойкумена, 2002. $336 \mathrm{c}$.

10. Черных Д.В. Локальные системы особо охраняемых природных территорий: реалии и перспективы: Монография. Новосибирск: Изд-во СО РАН, 2008. 88 с.

11. Шахбазян T.3., Проскурин В.С. Ландшафтно-рекреационный потенциал лесостепных ландшафтов Ставропольской возвышенности. Актуальные направления сбалансированного развития горных территорий в контексте междисциплинарного подхода: Материалы I Междунар. науч. конф. Карачаевск: КЧГУ, 2019. С. 279-283.

\section{REFERENCES}

1. Chernykh D.V. Local systems of specially protected natural territories: realities and prospects: Monograph. Novosibirsk: SB RAS Publishing House, 2008. 88 p. (in Russian).

2. Dirin D.A., Krupochkin E.P., Rygalo E.V. Geoinformation assessment of tourist and recreational potential of steppe territories (on the example of Kulunda steppe). InterCarto. Inter GIS. Geoinformation support of sustainable development of territories in the conditions of global climate change: Proceedings of the International conference. V. 23. Part 2. Moscow: Moscow University Press, 2017. P. 89-102 (in Russian).

3. Dunets A.N., Krupochkin E.P., Teltsova A.A. Assessment of tourist and recreational potential for the purposes of territorial planning. Izvestiya of Altai State University, 2011. No 3-2. Web resource: https://cyberleninka.ru/article/n/otsenka-turistsko-rekreatsionnogo-potentsiala-dlyatseley-territorialnogo-planirovaniya (accessed 13.11.2019) (in Russian).

4. Georgitsa I.M. Landscape-geographical approach to the construction of the ecological framework of cities (on the example of Yaroslavl). Abstract ... phD of geogr. sc. Astrakhan: Astrakhan State University, 2006. 20 p. (in Russian).

5. Ivanov A.N., Chizhova V.P. Protected natural areas: A textbook. Moscow: Moscow University Press, 2003. 119 p. (in Russian).

6. Kolbowski E.Yu. Landscape planning: study guide for university students. Moscow: Academy, 2008. 336 p. (in Russian).

7. Lopatkin D.A. Cartographic mapping and analysis of the ecological framework of the region (on the example of the lake Baikal basin). Abstract ... phD of geogr. sc. Irkutsk: Institute of Geography SB RAS, 2004. 23 p. (in Russian).

8. Lysenko A.V., Shakhbazyan T.Z. Landscape-ecological analysis of the network of specially protected natural territories of Stavropol Territory using geoinformation technologies. Third Intern. scientific. conf. with elements of a scientific school "Innovative methods and means of research in the field of atmospheric physics, hydrometeorology, ecology and climate change". Stavropol: Publishing House of NCFU, 2018. P. 285-287 (in Russian).

9. Rodoman B.B. Polarized biosphere: A collection of articles. Smolensk: Ojkumena, 2002. 336 p. (in Russian).

10. Shahbazyan T.Z., Proskurin V.S. Landscape and recreational potential of forest-steppe landscapes of Stavropol upland. Actual directions of balanced development of mountain territories in the context of interdisciplinary approach: proceedings of the I International scientific conference. Karachayevsk: KChSU, 2019. P. 279-283 (in Russian).

11. Vladimirov V.V., Fomin I.A. Fundamentals of district planning. Moscow: Higher school, 1995. 221 p. (in Russian). 